\title{
PENGARUH KECERDASAN EMOSIONAL, KOMITMEN ORGANISASIONAL, DAN BUDAYA ORGANISASI TERHADAP ORGANIZATIONAL CITIZENSHIP BEHAVIOR
}

\author{
Irene Goller ${ }^{1}$ \\ I Gusti Ayu Manuati Dewi \\ ${ }^{1,2}$ Fakultas Ekonomi dan Bisnis Universitas Udayana (Unud), Bali, Indonesia \\ email: nataliairene98@gmail.com
}

\begin{abstract}
ABSTRAK
Tujuan penelitian ini untuk menjelaskan pengaruhi kecerdasan emosional, komitmen organisasional dan budaya organisasi terhadap organizational citizenship behavior (OCB). Penelitian ini dilakukan di Fullmoon Villa Ubud. Jumlah populasi yang diambil adalah sebanyak 43 karyawan dengan menggunakan metode sampling jenuh. Pengumpulan data dilakukan dengan wawancara dan kuesioner. Teknik analisis yang digunakan pada penelitian ini adalah regresi linear berganda. Hasil penelitian menunjukkan bahwa kecerdasan emosional, komitmen organisasional, dan budaya organisasi berpengaruh positif dan signifikan terhadap OCB. Hal tersebut mengindikasikan bahwa semakin tinggi kecerdasan emosional dan komitmen organisasional karyawan serta semakin kuat budaya organisasi, maka perilaku kewargaan organisasional karyawan akan semakin meningkat.

Kata kunci : kecerdasan emosional, komitmen organisasional, budaya organisasi dan organizational citizenship behavior.
\end{abstract}

\begin{abstract}
The purpose of this study is to explain the influence of emotional intelligence, organizational commitment and organizational culture on organizational citizenship behavior (OCB). This research was conducted at Fullmoon Villa Ubud. The total population taken was 43 employees using the saturated sampling method. Data collection was carried out by interview and questionnaire. The analysis technique used in this study is multiple linear regression. The results showed that emotional intelligence, organizational commitment, and organizational culture had a positive and significant effect on $O C B$. This indicates that the higher the emotional intelligence and organizational commitment of employees and the stronger the organizational culture, the organizational citizenship behavior of employees will increase.

Keywords: emotional intelligence, organizational commitment, organizational culture and organizational citizenship behavior
\end{abstract}




\section{PENDAHULUAN}

Salah satu kunci keberhasilan organisasi saat ini yaitu sejauh mana warga organisasi secara sinergis mampu berkontribusi positif, baik dalam perencanaan maupun dalam proses pengimplementasian tugas dan tanggung jawab sebagai warga organisasi untuk mencapai tujuan organisasi. Menurut (Ardana dkk., 2012) Sumber Daya Manusia (SDM) adalah harta yang berharga dan paling penting dimiliki oleh suatu organisasi atau perusahaan. Perusahaan harus memperhatikan kinerja SDM pada perusahaan agar mampu mewujudkan tujuan yang telah ditetapkan sebelumnya, karena SDM merupakan penggerak dalam organisasi yang mampu memberikan efisiensi dalam pengelolaan suatu organisasi (Kumara dan Utama, 2016)

Semua organisasi yang ingin sukses saat ini, pasti memerlukan karyawan yang bertindak melebihi tugas pekerjaan umum mereka, yang akan memberikan kinerja melampaui perkiraan (Robbins, 2006). Perilaku yang dapat meningkatkan produktivitas karyawan dalam organisasi disebutkan dalam penelitian (Harper, 2015) yaitu OCB. Organizational Citizenship Behavior merupakan perilaku individual yang bersifat "discretionary" yang tidak secara langsung diakui oleh sistem imbalan formal dan secara bersama-sama akan mendorong fungsi organisasi lebih efektif (Organ, 2006). Terdapat bukti bahwa individu yang menunjukkan OCB memiliki kinerja lebih baik (Podsakoff et al., 1997).

Tiap-tiap individu dalam organisasi memiliki kepribadian yang beragam antara satu dengan yang lainnya. Hal ini dapat dilihat pada saat individu-individu dalam organisasi dihadapkan pada situasi tertentu. Karakter, perilaku serta respon mereka terhadap situasi dan keadaan yang dihadapinya pasti berbeda-beda. Dalam hal ini, kemampuan individu-individu dalam organisasi salah satunya dipengaruhi oleh kecerdasan emosional. Karena baik didalam dan diluar pekerjaan, perilaku individu juga akan berbeda saat berinteraksi dengan rekan kerjanya, beradaptasi dengan lingkungan kerjanya, serta dalam menghadapi konflik diorganisasinya.

Kecerdasan emosional adalah salah satu faktor yang mepengaruhi hubungan antara manajer dan anggota organisasi (Alavi et al., 2013). (Suwandewi dan Dewi, 2016) menyatakan bahwa kecerdasan emosional memiliki pengaruh yang kuat dan positif terhadap OCB. Kecerdasan emosional sebagai serangkaian kemampuan pribadi, emosi, dan sosial yang mempengaruhi kemampuan seseorang untuk berhasil dalam mengatasi tuntutan dan tekanan lingkungan (Ariati dkk., 2012). Selain kecerdasan emosional, menurut (Sutrisno, 2013) faktor lain yang mempengaruhi OCB adalah komitmen organisasional. Komitmen organisasional diindikasikan dalam tiga hal, yaitu keinginan kuat seseorang untuk tetap menjadi anggota organisasinya, kemauan untuk mengarahkan usahanya untuk organisasinya, serta keyakinan dan penerimaan yang kuat terhadap nilai-nilai dan tujuan organisasi. Komitmen organisasional akan membuat pegawai memberikan yang terbaik kepada organisasinya. Pegawai yang memiliki komitmen yang tinggi akan lebih berorientasi pada kerja, akan cenderung membantu dan dapat bekerjasama, yang merupakan bagian dari sikap OCB. Penelitian (Devi dan Adnyani, 2015) mengemukakan bahwa karyawan yang memiliki komitmen yang tinggi akan lebih sering berbicara secara positif tentang perusahaannya, membantu individu lain dan jauh melebihi harapan normal dalam pekerjaan mereka, 
melakukan pekerjaan dilandasi keinginan sendiri atau tanpa paksaan. Komitmen terhadap organisasi akan membuat karyawan setia pada organisasi dan bekerja dengan baik untuk kepentingan organisasi (Chamdam, 2013).

Budaya organisasi merupakan suatu sistem dari kepercayaan-kepercayaan dan nilai-nilai yang berkembang dalam organisasi dan mengarahkan perilaku anggotanya. Dalam bisnis, sistem ini sering dianggap Coorporate Culture. (Wijaya and Yuniawan, 2017) menyatakan bahwa semakin baik atau kuat budaya organisasi akan semakin meningkatkan OCB. Budaya organisasi memiliki tujuan untuk mengubah sikap dan juga perilaku SDM yang ada agar dapat meningkatkan produktivitas kerja untuk menghadapi berbagai tantangan di masa yang akan datang. (Oemar, 2013) menyatakan bahwa semakin positif pegawai dalam menilai budaya organisasi dan semakin terlibat ia dalam organisasi yang ada di instansinya, maka kecenderungan OCB akan meningkat pula (Arifin, 2015) menyatakan bahwa budaya organisasi adalah semua keyakinan, perasaan, perilaku dan simbol-simbol yang mencirikan suatu organisasi. Manfaat dari penerapan budaya organisasi yang baik adalah dapat meningkatkan kebersamaan, rasa kekeluargaan, saling terbuka satu sama lain, meningkatkan produktivitas kerja, membangun komunikasi yang lebih baik, tanggap dengan perkembangan dunia luar dan lain sebagainya yang sebagian besar merupakan bagian dari OCB.

Penelitian ini dilakukan di Fullmoon Villa Ubud yang terletak dikawasan Ubud dan dibangun berdasarkan permintaan akan penginapan atau akomodasi untuk memberikan pelayanan kepada turis dibidang jasa restauran dan spa. Akomodasi dengan tipe villa biasanya lebih disukai oleh wisatawan domestik maupun luar negeri yang menginginkan suasana yang lebih privat dan nyaman. Didalam menjalankan usahanya, Fullmoon Villa Ubud diperlukan karyawan yang memiliki kinerja yang maksimal agar dapat memberikan pelayanan yang baik. Oleh karena itu, karyawan dituntut untuk berkontribusi positif dengan melaksanakan OCB dalam setiap pekerjaannya.

Berdasarkan hasil wawancara awal yang telah dilakukan dengan general manager Fullmoon Villa Ubud terdapat permasalahan yang berkaitan dengan OCB, yaitu kurangnya keinginan karyawan untuk membantu rekan kerja yang memiliki beban kerja yang berlebih, kurangnya interaksi dengan sesama karyawan sehingga untuk memberi saran menjadi sulit saat menemukan masalah yang berkaitan dengan pekerjaannya, banyak karyawan yang mengeluh saat dihadapkan pada situasi yang kurang menguntungkan, kurangnya inisiatif dari karyawan untuk melakukan pekerjaan atas inisiatif sendiri, dan sedikitnya karyawan yang berpartisipasi dalam kegiatan-kegiatan perusahaan.

Rendahnya perilaku OCB pada karyawan tentunya akan berdampak pada kinerja karyawan secara keseluruhan. Mengetahui pentingnya OCB pada karyawan bagi kemajuan dan keberlangsungan perusahaan, maka OCB perlu dimunculkan dan ditingkatkan. Pemimpin organisasi harus memberikan contoh dan memperhatikan faktor yang mempengaruhi kemunculan OCB karyawan. Menurut (Titisari,2014:15), peningkatan OCB dipengaruhi oleh dua faktor utama yaitu faktor internal dan faktor eksternal. Faktor internal meliputi kepribadian, komitmen organisasional, moral karyawan, kepuasan kerja ,dan motivasi. Faktor eksternal meliputi budaya organisasi, kepercayaan, kepemimpinan situasional dan 
transformasional pada pimpinan. Perusahaan tentunya membutuhkan karyawan yang mampu mengendalikan emosinya serta mempunyai komitmen yang tinggi, dimana karyawan dengan komitmen organisasional yang tinggi akan mampu mengembangkan budaya organisasi yang optimal dan mampu berperilaku OCB sehingga dapat membantu perusahaan mencapai tujuan yang diinginkan.

Sesuai dengan latar belakang dan rumusan penelitian, maka penelitian ini bertujuan untuk: 1) menganalisis pengaruh kecerdasan emosional terhadap OCB karyawan di Fullmoon Villa Ubud, 2) menganalisis pengaruh komitmen organisasional terhadap OCB karyawan di Fullmoon Villa Ubud, 3) menganalisis pengaruh budaya organisasi terhadap OCB karyawan Fullmoon di Villa Ubud.

Penelitian yang dilakukan oleh (Jung dan Hye, 2012) menunjukkan bahwa kecerdasan emosional berpengaruh positif dan signifikan terhadap OCB karyawan. Berdasarkan hasil analisis faktor menunjukkan bahwa kecerdasan emosional menjadi faktor penting dalam meningkatkan OCB. Karyawan yang memahami, mengkontrol, dan menggunakan emosi secara efektif akan menciptakan lingkungan kerja yang positif dan signifikan meningkatkan perilaku karyawan seperti peningkatan OCB. Hasil penelitian yang dilakukan oleh (Suwandewi dan Dewi, 2016) menyatakan bahwa kecerdasan emosional berpengaruh positif dan signifikan terhadap OCB. Artinya, apabila kecerdasan emosional meningkat, maka OCB karyawan akan mengalami peningkatan juga. Penelitian (Asthenu, 2017) menunjukkan bahwa kecerdasan emosional berpengaruh positif dan signifikan terhadap OCB. Semakin baik kecerdasan emosional, maka akan memberikan dampak yang baik dalam meningkatkan OCB pegawai.

Menurut (Tumanggor dkk., 2017) terdapat pengaruh positif dan signifikan kecerdasan emosional terhadap OCB karyawan. Penelitian (Ibrahim, 2013) menyatakan bahwa kecerdasan emosional berpengaruh signifikan terhadap OCB. Artinya, semakin meningkat kemampuan karyawan dalam memotivasi diri yang disertai dengan kesadaran diri yang tinggi, maka akan diikuti oleh peningkatan perilaku OCB karyawan. Hasil penelitian (Sabahi dan Dashti, 2016); (Bavarsad dan Rahimi, 2016), (Hosseini dan Zirak, 2016) dimana hasilnya juga menunjukkan bahwa kecerdasan emosional berpengaruh positif dan signifikan terhadap OCB. Berdasarkan penelitian sebelumnya dapat dirumuskan hipotesis sebagai berikut: $\mathrm{H}_{1}$ : Kecerdasan emosional berpengaruh positif dan signifikan terhadap OCB

Penelitian (Pratama dan Mujiati, 2019) menyatakan komitmen organisasional berpengaruh positif dan signifikan terhadap OCB. Hal ini memiliki makna bahwa pegawai yang memiliki komitmen organisasional yang tinggi akan dengan sendirinya menimbulkan perilaku OCB pada pegawai. Penelitian yang dilakukan (Faradita, 2017), menunjukkan bahwa komitmen organisasional berpengaruh signifikan terhadap OCB. Karyawan yang memiliki komitmen tinggi akan lebih sering berbicara secara positif tentang perusahaannya, membantu individu lain dan jauh melebihi harapan normal dalam pekerjaan mereka, selain itu karyawan melakukan pekerjaan dilandasi keinginan sendiri atau tanpa paksaan (Devi dan Adnyani, 2015).

(Diatmika dan Suwandana, 2016) menunjukkan bahwa komitmen organisasional berpengaruh positif dan signifikan terhadap OCB. (Han et al., 2016) dalam penelitiannya juga menemukan bahwa komitmen organisasional 
memberikan pengaruh yang positif terhadap OCB. Penelitian yang dilakukan oleh (Bakan et al., 2013) dalam penelitiannya menyatakan bahwa ada hubungan yang signifikan antara komitmen organisasional dan OCB dikalangan perempuan pekerja di sektor tekstil. Hasil penelitian (Ortiz et al., 2015) yang dilakukan pada karyawan bank menyatakan dalam penelitiannya terdapat pengaruh positif dan signifikan antara komitmen organisasional terhadap OCB. Hasil penelitian (Hasani et al., 2013), (Suparta dkk., 2013), (Barusman dan Mihdar, 2014) juga menyatakan komitmen organisasional berpengaruh positif terhadap OCB. Berdasarkan penelitian sebelumnya dapat dirumuskan hipotesis sebagai berikut:

$\mathrm{H}_{2}$ : Komitmen organisasional berpengaruh positif dan signifikan terhadap OCB

Penelitian yang dilakukan oleh (Hamza, 2015) menunjukkan bahwa budaya organisasi berpengaruh positif dan signifikan terhadap OCB. Penelitian dari (Kurniawan et al., 2016) menunjukkan bahwa budaya organisasi berpengaruh signifikan terhadap OCB. Sementara itu Penelitian (Wijaya dan Yuniawan, 2017) menyatakan bahwa budaya organisasi berpengaruh positif dan signifikan terhadap OCB. Hal ini dapat dilihat dari semakin baik atau kuat budaya organisasi akan semakin meningkatkan OCB karyawan. Menurut (Maulani dkk., 2015) hasil penelitiannya diketahui terdapat pengaruh yang signifikan budaya organisasi terhadap OCB.

Menurut penelitian (Oemar, 2013) menyatakan bahwa semakin positif pegawai dalam menilai budaya organisasi dan semakin terlibat ia dalam organisasi yang ada di instansinya, maka kecenderungan OCB akan meningkat pula. (Mahardika dan Wibawa, 2019) menyatakan bahwa budaya organisasi memiliki pengaruh positif dan signifikan terhadap OCB. Hal ini menunjukan bahwa ketika budaya organisasi diterapkan dengan sangat baik didalam organisasi maka akan meningkatkan sikap OCB pada karyawan dalam organisasi. Penelitian dari (Jain, 2015) juga memberikan bukti bahwa budaya organisasi berpengaruh positif dan signifikan terhadap OCB. Penelitian (Yaseen et al., 2015), (Kim, 2014) turut serta juga memberikan bukti bahwa budaya organisasi berpengaruh positif dan signifikan terhadap OCB. Berdasarkan penelitian sebelumnya dapat dirumuskan hipotesis sebagai berikut:

$\mathrm{H}_{3}$ : Budaya organisasi berpengaruh positif dan signifikan terhadap OCB Berdasarkan pendahuluan dan pengembangan hipotesis,maka kerangka konseptual dalam penelitian ini disajikan dalam Gambar 1 sebagai berikut :

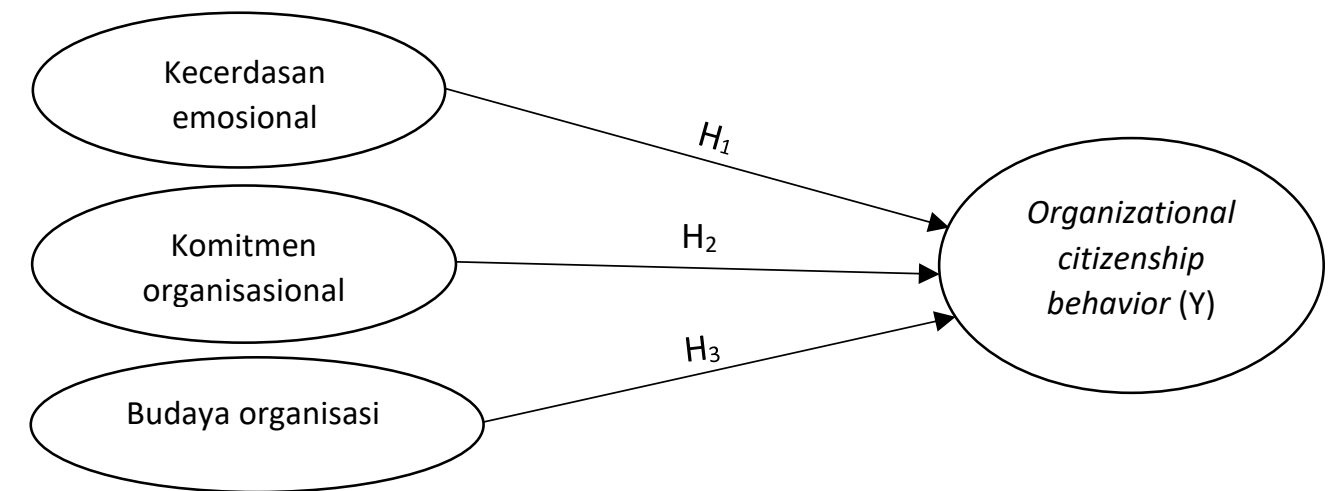

Gambar 1. Kerangka Konseptual 


\section{METODE PENELITIAN}

Desain penelitian yang digunakan dalam penelitian ini bersifat asosiatif dengan tujuan mengetahui pengaruh atau hubungan antara dua variabel atau lebih. Penelitian ini dilakukan di Fullmoon Villa Ubud yang beralamat di Jalan Jineng, Lodtunduh, Kecamatan Ubud, Kabupaten Gianyar, Bali. Lokasi ini dipilih sebagai lokasi penelitian karena terdapat masalah yang berkaitan dengan OCB.

Variabel terikat dalam penelitian ini adalah organizational citizenship behavior. Organizational citizenship behavior merupakan perilaku yang bersifat sukarela, bukan merupakan tindakan yang terpaksa terhadap hal-hal yang mengedepankan kepentingan perusahaan. Menurut (Organ et al., 2006), ada lima indikator dari OCB yaitu :1) altruism, 2) conscientiousness, 3) sportmanship, 4) courtessy, dan 5) civic virtue.

Variabel bebas dalam penelitian ini adalah kecerdasan emosional, komitmen organisasional, dan budaya organisasi. Kecerdasan emosional merupakan kemampuan seseorang mengatur kehidupan emosinya. Menurut (Salovey dan Mayer, 2006), mengungkapkan lima indikator kecerdasan emosional yang dapat menjadi pedoman bagi individu untuk mencapai kesuksesan, yaitu: 1) self awareness (kesadaran diri), 2) self regulation (pengaturan diri), 3) motivation (motivasi), 4) empathy (empati), 5) social skill (keterampilan sosial). komitmen organisasional merupakan suatu keadaan psikologis yang dikarakteristikkan dengan meyakini dan menerima tujuan dan nilai yang dimiliki oleh organisasi, kesediaan untuk berusaha dengan sungguh-sungguh demi organisasi, mempunyai keinginan yang kuat untuk tetap menjadi anggota organisasi. Dalam penelitian ini indikator yang digunakan utuk mengukur komitmen organisasional yang diacu oleh (Widyanto dkk., 2013) meliputi sebagai berikut : 1) komitmen afektif (affective commitment), 2) komitmen bersinambung (continuance commitment), 3) komitmen normatif (normative commitment). Budaya organisasi adalah nilai-nilai dan normanorma yang diterapkan dalam organisasi sebagai asumsi dasar dalam mempengaruhi perilaku karyawan dalam melaksanakan pekerjaannya dalam organisasi. Menurut (Brahmasari and Siregar 2009) terdapat tujuh indikator yang dapat mengukur budaya organisasi: 1) tujuan perusahaan, 2) konsensus, 3) keunggulan, 4) kesatuan, 5) prestasi, 6) keakraban, 7) integrasi.

Data kuantitatif dalam penelitian ini berupa data dalam bentuk angka yaitu data jumlah karyawan dan skor jawaban responden terhadap pernyataan yang terdapat di dalam kuesioner. Data kualitatif dalam penelitian ini yaitu sejarah Fullmoon Villa Ubud, daftar nama karyawan dan pernyataan dari Skala Likert. Sumber primer dalam penelitian ini adalah data yang didapat dari wawancara langsung, kuesioner, serta skor jawaban dari butir-butir pernyataan kuesioner yang disebarkan. Sumber sekunder dalam penelitian ini adalah sejarah singkat perusahaan, dan gambaran umum perusahaan yang diperoleh Fullmoon Villa Ubud. Responden penelitian ini adalah 43 karyawan, pimpinan dan manajer tidak menjadi responden dalam penelitian ini karena yang diteliti hanya seluruh karyawan Fullmoon Villa Ubud. Berdasarkan pernyataan tersebut jumlah populasi kurang dari 100 responden maka pada penelitian ini menggunakan teknik sampel jenuh.

Penelitian ini menggunakan dua metode pengambilan data yakni metode wawancara dan kuesioner. Wawancara merupakan metode pengumpulan data 
dengan cara tanya jawab secara langsung dengan pihak Fullmoon Villa Ubud. Kuesioner merupakan metode pengumpulan data yang dilakukan menggunakan daftar pernyataan tertulis yang disebarkan kepada karyawan Fullmoon Villa Ubud. Pengukuran variabel dilakukan dengan menggunakan Skala Likert. Skala ini digunakan untuk mengukur sikap, pendapat, dan tanggapan seseorang mengenai suatu kegiatan. Dalam kuesioner ini pernyataan tertutup menggunakan Skala Likert 1 sampai 5, dari Sangat Tidak Setuju (STS) sampai Sangat Setuju (SS).

\section{HASIL DAN PEMBAHASAN}

Responden dalam penelitian ini menunjukkan jumlah karyawan perempuan hampir sama dengan laki-laki karena alasan kebutuhan villa yaitu dibagian kitchen, therapist, front office dan house keeping. Kelompok usia yang dominan adalah pada usia 18-25 tahun. Hal tersebut dikarenakan perusahaan lebih banyak membutuhkan karyawan yang masih muda dalam menjalankan perusahannya. Misalnya dibagian waiterss/waiter dan therapist. Responden yang dominan berdasarkan pendidikan adalah pada tingkat lulusan SMA. Hal tersebut dikarenakan tingkat pendidikan yang tinggi tidak terlalu dibutuhkan, sehingga karyawan dengan pendidikan terakhir SMA sudah cukup untuk bekerja di villa seperti dibagian therapist dan house keeping. Responden yang dominan berdasarkan masa kerja adalah masa kerja selama 1-3 tahun. Perusahaan banyak merekrut karyawan dengan pendidikan terakhir lulusan SMA, dikarenakan mereka bekerja untuk menambah pengalaman.

Tabel 1.

Karakteristik Responden Karyawan Fullmoon Villa Ubud Tahun 2019

\begin{tabular}{|c|c|c|c|c|}
\hline \multirow{2}{*}{ No } & \multirow{2}{*}{ Karakteristik } & \multirow{2}{*}{ Klasifikasi } & \multicolumn{2}{|c|}{ Jumlah } \\
\hline & & & Orang & Presentase $(\%)$ \\
\hline \multirow{4}{*}{1} & \multirow{2}{*}{ Jenis kelamin } & Laki-laki & 21 & 49 \\
\hline & & Perempuan & 22 & 51 \\
\hline & \multirow[t]{2}{*}{ Jumlah } & & 43 & 100 \\
\hline & & 18-25 tahun & 24 & 56 \\
\hline \multirow{4}{*}{2} & \multirow{3}{*}{ Usia (Tahun) } & 26-35 tahun & 8 & 19 \\
\hline & & $36-45$ tahun & 7 & 16 \\
\hline & & $>45$ tahun & 4 & 9 \\
\hline & Jumlah & & 43 & 100 \\
\hline \multirow[t]{4}{*}{3} & \multirow[t]{2}{*}{ Pendidikan terakhir } & SMA/Sederajat & 31 & 72 \\
\hline & & Diploma & 12 & 28 \\
\hline & \multirow[t]{2}{*}{ Jumlah } & & 43 & 100 \\
\hline & & $<1$ Tahun & 12 & 28 \\
\hline \multirow{4}{*}{4} & \multirow{3}{*}{ Masa kerja } & 1-3 Tahun & 13 & 30 \\
\hline & & 4-6 Tahun & 9 & 21 \\
\hline & & $>6$ Tahun & 9 & 21 \\
\hline & Jumlah & & 43 & 100 \\
\hline
\end{tabular}

Sumber: Data diolah, 2019

Hasil uji validitas pada Tabel 2. menunjukan bahwa semua variabel memiliki koefisien korelasi dengan skor total seluruh butir pernyataan lebih besar dari 0,30 . Jadi dapat dinyatakan bahwa butir-butir pernyataan dalam instrumen penelitian tersebut dikatakan valid. 
Tabel 2.

Rekapitulasi Hasil Uji Validitas Instrumen Penelitian

\begin{tabular}{lccc}
\hline Variabel & Indikator & Koefisien Korelasi & Ket. \\
\hline Kecerdasan Emosional (X1) & X1.1 & 0,739 & Valid \\
& X1.2 & 0,722 & Valid \\
& X1.3 & 0,581 & Valid \\
& X1.4 & 0,602 & Valid \\
Komitmen Organisasional (X2) & X1.5 & 0,768 & Valid \\
& X2.1 & 0,869 & Valid \\
& X2.2 & 0,489 & Valid \\
& X2.3 & 0,424 & Valid \\
& X2.4 & 0,832 & Valid \\
& X2.5 & 0,819 & Valid \\
& X2.6 & 0,760 & Valid \\
& X2.7 & 0,634 & Valid \\
& X2.8 & 0,782 & Valid \\
Budaya Organisasi (X3) & X2.9 & 0,730 & Valid \\
& X3.1 & 0,530 & Valid \\
& X3.2 & 0,584 & Valid \\
& X3.3 & 0,569 & Valid \\
& X3.4 & 0,638 & Valid \\
& X3.5 & 0,844 & Valid \\
& X3.6 & 0,703 & Valid \\
& X3.7 & 0,771 & Valid \\
& Y.1 & 0,844 & Valid \\
& Y.2 & 0,718 & Valid \\
& Y.3 & 0,661 & Valid \\
& Y.4 & 0,870 & Valid \\
& Y.5 & 0,634 & Valid \\
\hline
\end{tabular}

Sumber: Data diolah, 2019

Tabel 3.

Rekapitulasi Uji Reliabilitas Instrumen Penelitian

\begin{tabular}{cccc}
\hline No. & Variabel & Cronbach's Alpha & Keterangan \\
\hline 1. & Kecerdasan Emosional & 0,702 & Reliabel \\
2. & Komitmen Organisasional & 0,818 & Reliabel \\
3. & Budaya Organisasi & 0,786 & Reliabel \\
4. & Organizational Citizenship Behavior & 0,797 & Reliabel \\
\hline
\end{tabular}

Sumber: Data diolah, 2019

Hasil uji reliabilitas pada Tabel 3. menunjukkan bahwa seluruh instrumen penelitian memiliki nilai koefisien Cronbach's Alpha lebih dari 0,60. Jadi dapat dinyatakan bahwa seluruh variabel telah memenuhi syarat reliablitas atau kehandalan sehingga dapat digunakan untuk melakukan penelitian.

Tabel 4. menunjukkan bahwa lima butir pernyataan mengenai OCB memperoleh rata-rata sebesar 4,27 ini menunjukkan bahwa OCB yang dirasakan karyawan tergolong sangat tinggi. Indikator yang mempunyai rata-rata skor tertinggi ditunjukkan pada pernyataan "Saya selalu ikut berpartisipasi dalam berbagai kegiatan yang diselenggarakan oleh organisasi." dengan nilai rata-rata sebesar 4,56 ini berarti karyawan mau ikut berpartisipasi dalam kegiatan eksternal dan internal yang diselenggarakan Fullmoon Villa Ubud. Indikator yang 
mempunyai rata-rata skor yang paling rendah dibanding rata-rata skor secara keseluruhan adalah indikator pada pernyataan "Saya mau melakukan pekerjaan lebih walaupun tidak ada yang meminta atau menyuruh." sebesar 3,67 menunjukkan bahwa masih rendahnya karyawan yang mau melakukan pekerjaan lebih tanpa menunggu perintah dari atasan.

Tabel 4.

Deskripsi Jawaban Responden terhadap Indikator OCB

\begin{tabular}{|c|c|c|c|c|c|c|c|c|}
\hline \multirow[b]{2}{*}{ No } & \multirow[b]{2}{*}{ Pernyataan } & \multicolumn{5}{|c|}{ Skor Jawaban } & \multirow[b]{2}{*}{$\begin{array}{l}\text { Rata- } \\
\text { rata }\end{array}$} & \multirow[b]{2}{*}{ Ket. } \\
\hline & & $\begin{array}{l}\text { STS } \\
(1)\end{array}$ & $\begin{array}{l}\text { TS } \\
(2)\end{array}$ & $\begin{array}{l}\text { C } \\
\text { (3) }\end{array}$ & $\begin{array}{c}S \\
(4)\end{array}$ & $\begin{array}{l}\text { SS } \\
(5)\end{array}$ & & \\
\hline 1. & $\begin{array}{l}\text { Saya bersedia membantu rekan } \\
\text { kerja yang beban kerjanya } \\
\text { berlebihan }\end{array}$ & 0 & 0 & 4 & 26 & 13 & 4,21 & Tinggi \\
\hline 2. & $\begin{array}{l}\text { Saya sangat menghargai sesama } \\
\text { rekan kerja saya apapun jabatannya }\end{array}$ & 0 & 0 & 2 & 20 & 21 & 4,44 & $\begin{array}{l}\text { Sangat } \\
\text { Tinggi }\end{array}$ \\
\hline 3. & $\begin{array}{l}\text { Saya selalu menerima kebijakan } \\
\text { yang berlaku ditempat saya } \\
\text { bekerja }\end{array}$ & 0 & 0 & 2 & 19 & 22 & 4,47 & $\begin{array}{l}\text { Sangat } \\
\text { Tinggi }\end{array}$ \\
\hline 4. & $\begin{array}{l}\text { Saya mau melakukan pekerjaan } \\
\text { lebih walaupun tidak ada yang } \\
\text { meminta atau menyuruh }\end{array}$ & 0 & 4 & 15 & 15 & 9 & 3,67 & Tinggi \\
\hline 5. & $\begin{array}{l}\text { Saya selalu ikut berpartisipasi } \\
\text { dalam berbagai kegiatan yang } \\
\text { diselenggarakan oleh organisasi }\end{array}$ & 0 & 0 & 0 & 19 & 24 & 4,56 & $\begin{array}{l}\text { Sangat } \\
\text { Tinggi }\end{array}$ \\
\hline & Rata-rata skor & & & & & & 4,27 & $\begin{array}{l}\text { Sangat } \\
\text { Tinggi }\end{array}$ \\
\hline
\end{tabular}

Tabel 5. menunjukkan bahwa lima butir pernyataan mengenai kecerdasan emosional memperoleh rata-rata sebesar 4,03 ini menunjukkan bahwa kecerdasan emosional yang dirasakan karyawan tergolong tinggi. Indikator yang mempunyai rata-rata skor tertinggi ditunjukkan pada pernyataan "Saya dapat memotivasi diri saya sendiri dalam mencapai sasaran karir" dengan nilai rata-rata sebesar 4,28 ini berarti karyawan dapat memotivasi diri sendiri dalam mencapai sasaran karir diperusahaan. Indikator yang mempunyai rata-rata skor yang paling rendah dibanding rata-rata skor secara keseluruhan adalah indikator pada pernyataan "Saya dapat mengerti emosi orang lain" sebesar 3,63 menunjukkan bahwa sebagian karyawan belum dapat mengerti emosi antar rekan kerjanya diperusahaan.

Tabel 6. menunjukkan bahwa sembilan butir pernyataan mengenai komitmen organisasional memperoleh rata-rata sebesar 3,66 ini menunjukkan bahwa komitmen organisasional yang dimiliki karyawan tergolong tinggi. Indikator yang mempunyai rata-rata skor tertinggi ditunjukkan pada pernyataan "Saya menjadi bagian keluarga pada perusahaan ini." dengan nilai rata-rata sebesar 4,30 ini berarti karyawan merasa dirinya telah menjadi bagian keluarga dalam perusahaan. Indikator yang mempunyai rata-rata skor yang paling rendah dibanding rata-rata skor secara keseluruhan adalah indikator pada pernyataan "Saya sulit meninggalkan perusahaan ini karena takut tidak mendapatkan kesempatan kerja di tempat lain" sebesar 3,21 menunjukkan bahwa sebagian karyawan belum merasa sulit dan takut jika harus meninggalkan perusahaan. 
Tabel 5.

Deskripsi Jawaban Responden terhadap Indikator Kecerdasan Emosional

\begin{tabular}{|c|c|c|c|c|c|c|c|c|}
\hline \multirow[b]{2}{*}{ No } & \multirow[b]{2}{*}{ Pernyataan } & \multicolumn{5}{|c|}{ Skor Jawaban } & \multirow[b]{2}{*}{$\begin{array}{c}\text { Rata- } \\
\text { rata }\end{array}$} & \multirow[b]{2}{*}{ Ket. } \\
\hline & & $\begin{array}{c}\text { STS } \\
(1)\end{array}$ & $\begin{array}{l}\text { TS } \\
(2)\end{array}$ & $\begin{array}{l}\mathrm{C} \\
(3)\end{array}$ & $\begin{array}{c}S \\
(4)\end{array}$ & $\begin{array}{l}\text { SS } \\
(5)\end{array}$ & & \\
\hline 1. & $\begin{array}{l}\text { Saya dapat memahami emosi yang } \\
\text { terjadi pada diri saya }\end{array}$ & 0 & 1 & 5 & 25 & 12 & 4,12 & Tinggi \\
\hline 2. & $\begin{array}{l}\text { Saya mampu mengendalikan emosi } \\
\text { diri sendiri }\end{array}$ & 0 & 2 & 6 & 20 & 15 & 4,12 & Tinggi \\
\hline 3. & $\begin{array}{l}\text { Saya dapat memotivasi diri saya } \\
\text { sendiri dalam mencapai sasaran } \\
\text { karir }\end{array}$ & 1 & 0 & 3 & 22 & 17 & 4,28 & $\begin{array}{l}\text { Sangat } \\
\text { Tinggi }\end{array}$ \\
\hline 4. & $\begin{array}{l}\text { Saya dapat mengerti emosi orang } \\
\text { lain. }\end{array}$ & 0 & 0 & 23 & 13 & 7 & 3,63 & Tinggi \\
\hline 5. & $\begin{array}{l}\text { Saya memiliki ketrampilan sosial } \\
\text { dalam menjalani hubungan kerja } \\
\text { sama dengan baik }\end{array}$ & 0 & 1 & 4 & 32 & 6 & 4,00 & Tinggi \\
\hline & Rata-rata skor & & & & & & 4,03 & Tinggi \\
\hline
\end{tabular}

Sumber: Data diolah, 2019

Tabel 6.

Deskripsi Jawaban Responden terhadap Indikator KomitmenOrganisasional

\begin{tabular}{|c|c|c|c|c|c|c|c|c|}
\hline \multirow[b]{2}{*}{ No } & \multirow[b]{2}{*}{ Pernyataan } & \multicolumn{5}{|c|}{ Skor Jawaban } & \multirow[b]{2}{*}{$\begin{array}{c}\text { Rata- } \\
\text { rata }\end{array}$} & \\
\hline & & $\begin{array}{c}\text { STS } \\
\text { (1) }\end{array}$ & $\begin{array}{l}\text { TS } \\
(2)\end{array}$ & $\begin{array}{c}\mathrm{C} \\
\text { (3) }\end{array}$ & $\underset{(\mathbf{4})}{\mathbf{S}}$ & $\begin{array}{l}\text { SS } \\
(5)\end{array}$ & & Ket. \\
\hline
\end{tabular}

Komitmen afektif

Saya akan merasa sangat berbahagia

1. menghabiskan sisa karir saya di perusahaan ini.

2. Saya merasa masalah yang terjadi di perusahaan menjadi masalah saya juga.

3. Saya menjadi bagian keluarga pada perusahaan ini.

$\begin{array}{lllll}\text { (1) } & \text { (2) } & \text { (3) } & \text { (4) } & \text { (5) }\end{array}$

Komitmen bersinambung

Saya sulit meninggalkan perusahaan ini

4. karena takut tidak mendapatkan

kesempatan kerja di tempat lain.

$\begin{array}{lllllll}1 & 2 & 16 & 14 & 10 & 3,70 & \text { Tinggi }\end{array}$

$\begin{array}{lllllll}1 & 0 & 7 & 31 & 4 & 3,86 & \text { Tinggi }\end{array}$

$\begin{array}{lllllll}0 & 0 & 8 & 14 & 21 & 4,30 & \text { Tinggi }\end{array}$

Akan terlalu merugikan bagi saya untuk

5. meninggalkan perusahaan ini.

Sulit mendapatkan pekerjaan dengan

$\begin{array}{llllllllll}\text { 6. } & \text { penghasilan yang bagus seperti pekerjaan } & 1 & 10 & 10 & 17 & 5 & 3,35 & \text { Cukup }\end{array}$ saya sekarang.

Komitmen normatif

7. Saya merasa perusahaan ini telah banyak

berjasa bagi hidup saya.

8. Saya merasa belum memberikan banyak

8. kontribusi bagi perusahaan ini.

9. Perusahaan ini layak mendapatkan kesetiaan dari saya. 
Tabel 7.

Deskripsi Jawaban Responden terhadap Indikator Budaya Organisasi

\begin{tabular}{|c|c|c|c|c|c|c|c|c|}
\hline \multirow[b]{2}{*}{ No } & \multirow[b]{2}{*}{ Pernyataan } & \multicolumn{5}{|c|}{ Skor Jawaban } & \multirow[b]{2}{*}{$\begin{array}{l}\text { Rata- } \\
\text { rata }\end{array}$} & \multirow[b]{2}{*}{ Ket. } \\
\hline & & $\begin{array}{c}\text { STS } \\
\text { (1) }\end{array}$ & $\begin{array}{l}\text { TS } \\
\text { (2) }\end{array}$ & $\begin{array}{c}\mathrm{C} \\
\text { (3) }\end{array}$ & $\begin{array}{c}S \\
(4)\end{array}$ & $\begin{array}{l}\text { SS } \\
(5)\end{array}$ & & \\
\hline 1. & Saya memahami tujuan dari Perusahaan & 0 & 0 & 2 & 34 & 7 & 4,12 & Kuat \\
\hline 2. & $\begin{array}{l}\text { Aspirasi karyawan dapat disampaikan } \\
\text { secara langsung terkait kebijakan } \\
\text { Perusahaan }\end{array}$ & 0 & 0 & 2 & 34 & 7 & 4,12 & Kuat \\
\hline 3. & $\begin{array}{l}\text { Saya selalu menerapkan nilai-nilai yang } \\
\text { ada di dalam Perusahaan }\end{array}$ & 0 & 0 & 4 & 30 & 9 & 4,12 & Kuat \\
\hline 4. & $\begin{array}{l}\text { Pemberian reward dari Perusahaan } \\
\text { kepada karyawan berdasarkan atas } \\
\text { kinerja karyawan }\end{array}$ & 0 & 0 & 9 & 12 & 22 & 4,30 & $\begin{array}{c}\text { Sangat } \\
\text { Kuat }\end{array}$ \\
\hline 5. & $\begin{array}{l}\text { Pimpinan memperhatikan kinerja setiap } \\
\text { karyawan. }\end{array}$ & 0 & 2 & 2 & 31 & 8 & 4,05 & Kuat \\
\hline 6. & $\begin{array}{l}\text { Komunikasi antar karyawan terjalin } \\
\text { dengan baik di Perusahaan }\end{array}$ & 0 & 2 & 1 & 20 & 20 & 4,35 & $\begin{array}{c}\text { Sangat } \\
\text { Kuat }\end{array}$ \\
\hline 7. & $\begin{array}{l}\text { Karyawan bekerjasama untuk mencapai } \\
\text { tujuan Perusahaan }\end{array}$ & 0 & 1 & 4 & 15 & 23 & 4,40 & $\begin{array}{c}\text { Sangat } \\
\text { Kuat }\end{array}$ \\
\hline & Rata-rata skor & & & & & & 4,21 & $\begin{array}{c}\text { Sangat } \\
\text { Kuat }\end{array}$ \\
\hline
\end{tabular}

Sumber: Data diolah, 2019

Tabel 7. menunjukkan bahwa tujuh butir pernyataan mengenai budaya organisasi memperoleh rata-rata sebesar 4,21 ini menunjukkan bahwa budaya organisasi yang dirasakan karyawan tergolong sangat kuat. Indikator yang mempunyai rata-rata skor tertinggi ditunjukkan pada pernyataan "Karyawan bekerjasama untuk mencapai tujuan Fullmoon Villa Ubud." dengan nilai rata-rata sebesar 4,40 ini berarti setiap karyawan mampu bekerjasama untuk mencapai tujuan Fullmoon Villa Ubud. Indikator yang mempunyai rata-rata skor yang paling rendah dibanding rata-rata skor secara keseluruhan adalah indikator pada pernyataan "Pimpinan memperhatikan kinerja setiap karyawan." sebesar 4,05 menunjukkan bahwa pemimpin sudah cukup memperhatikan kinerja setiap karyawan dengan baik.

Tabel 8.

Hasil Analisis Regresi Linier Berganda

\begin{tabular}{|c|c|c|c|c|c|}
\hline \multirow[b]{2}{*}{ Model } & \multicolumn{2}{|c|}{$\begin{array}{c}\text { Unstandardized } \\
\text { Coefficients }\end{array}$} & \multirow{2}{*}{$\begin{array}{c}\text { Standardized } \\
\text { Coefficients } \\
\text { Beta }\end{array}$} & \multirow[b]{2}{*}{$\mathbf{T}$} & \multirow[b]{2}{*}{ Sig. } \\
\hline & B & Std. Error & & & \\
\hline (constant) & 0,412 & 0,575 & & 0,717 & 0,478 \\
\hline Kecerdasan emosional & 0,273 & 0,115 & 0,271 & 2,370 & 0,023 \\
\hline Komitmen organisasional & 0,228 & 0,106 & 0,306 & 2,159 & 0,037 \\
\hline Budaya organisasi & 0,457 & 0,172 & 0,400 & 2,662 & 0,011 \\
\hline $\mathrm{R}$ square & 0,571 & & & & \\
\hline Sig. F &, $000^{\mathrm{b}}$ & & & & \\
\hline $\mathrm{F}$ & 17,282 & & & & \\
\hline
\end{tabular}

Sumber: Data diolah, 2019 


$$
\mathrm{Y}=0,412+0,273 \mathrm{X}_{1}+0,228 \mathrm{X}_{2}+0,457 \mathrm{X}_{3}
$$

Nilai koefisien variabel kecerdasan emosional $\left(\mathrm{X}_{1}\right)$ sebesar 0,271 , berarti terdapat hubungan positif antara kecerdasan emosional dan organizational citizenship behavior (Y). Sehingga dapat disimpulkan bahwa kecerdasan emosional berpengaruh positif terhadap organizational citizenship behavior pada karyawan Fullmoon Villa Ubud. Nilai koefisien variabel komitmen oganisasional $\left(\mathrm{X}_{2}\right)$ sebesar 0,306 berarti terdapat hubungan positif antara komitmen oganisasional dan organizational citizenship behavior (Y). Sehingga dapat disimpulkan bahwa komitmen oganisasional berpengaruh positif terhadap organizational citizenship behavior pada karyawan Fullmoon Villa Ubud. Nilai koefisien variabel budaya organisasi $\left(\mathrm{X}_{3}\right)$ sebesar 0,400 berarti terdapat hubungan positif antara komitmen oganisasional dan organizational citizenship behavior (Y). Sehingga dapat disimpulkan bahwa komitmen oganisasional berpengaruh positif terhadap organizational citizenship behavior pada karyawan Fullmoon Villa Ubud.

Berdasarkan Tabel 8. menunjukkan nilai sig sebesar, $000^{\mathrm{b}}$ yang lebih kecil dari $0,05\left(, 000^{\mathrm{b}}<0,05\right)$ yang berarti variabel bebas yaitu kecerdasan emosional $\left(\mathrm{X}_{1}\right)$, komitmen organisasional $\left(\mathrm{X}_{2}\right)$, budaya organisasi $\left(\mathrm{X}_{3}\right)$ berpengaruh signifikan secara serempak atau bersama-sama terhadap variabel terikat yaitu OCB (Y), sehingga penelitian ini dapat dikatakan memenuhi uji kelayakan model atau model penelitian ini dinyatakan layak digunakan sebagai model regresi. Berdasarkan hasil uji pada Tabel 4.12 nilai $R$ Square sebesar 0,571. Sehingga dapat dihitung persentase kontribusi kecerdasan emosional, komitmen organisasional, budaya organisasi terhadap OCB sebesar $0,571 \times 100$ persen $=57,1 \%$ persen dan sisanya 42,9 persen dipengaruhi oleh variabel lain di luar penelitian.

Berdasarkan hasil regresi linier berganda Tabel 8. diketahui nilai koefisien beta variabel kecerdasan emosional bernilai positif yakni 0,271 dengan nilai sig sebesar 0,023. Nilai Sig. 0,023 <0,05 mengindikasikan bahwa $\mathrm{H}_{1}$ diterima. Dengan kata lain kecerdasan emosional berpengaruh positif signifikan terhadap OCB. Nilai koefisien beta variabel komitmen organisasional bernilai positif yakni 0,306 dengan nilai sig sebesar 0,037. Nilai Sig. 0,037 <0,05 mengindikasikan bahwa $\mathrm{H}_{1}$ diterima. Dengan kata lain komitmen organisasional berpengaruh positif signifikan terhadap OCB. Nilai koefisien beta variabel budaya organisasi bernilai positif yakni 0,400 dengan nilai sig sebesar 0,011. Nilai Sig. 0,011 <0,05 mengindikasikan bahwa $\mathrm{H}_{1}$ diterima. Dengan kata lain budaya organisasi berpengaruh positif signifikan terhadap OCB.

Tabel 9.

Hasil Uji Normalitas

\begin{tabular}{cc}
\hline & Unstandardized Residual \\
\hline $\mathrm{N}$ & 43 \\
Kolmogorov-Smirnov Z & 0,812 \\
Asymp. Sig. (2-tailed) & 0,525
\end{tabular}

Sumber: Data diolah, 2019 
Tabel 9. menunjukkan bahwa nilai Asymp. Sig. (2-tailed) Kolmogorov Smirnov (K-S) sebesar 0,525. Hasil tersebut mengidentifikasi bahwa model persamaan regresi tersebut berdistribusi normal karena nilai Asymp. Sig. (2-tailed) Kolmogorov Smirnov lebih besar dari alpha 0,05.

Tabel 10.

Hasil Uji Multikolinearitas

\begin{tabular}{lcc}
\hline & \multicolumn{2}{c}{ Colinearity Statistic } \\
Model & Tolerance & VIF \\
\hline Kecerdasan Emosional $\left(\mathrm{X}_{1}\right)$ & 0,842 & 1,187 \\
Komitmen Organisasional $\left(\mathrm{X}_{2}\right)$ & 0,550 & 1,819 \\
Budaya Organisasi $\left(\mathrm{X}_{3}\right)$ & 0,488 & 2,049 \\
\hline
\end{tabular}

Sumber: Data diolah, 2019

Tabel 10. menunjukkan nilai tolerance dan VIF dari seluruh variabel bebas. Berdasarkan hasil analisis, dapat dilihat bahwa koefisien tolerance semua variabel lebih besar dari 0,10 dan nilai VIF lebih kecil dari 10. Hasil ini mengindikasikan bahwa tidak terdapat gejala multikolinearitas.

Tabel 11.

Uji Heteroskedastisitas

\begin{tabular}{lcccccc}
\hline & & \multicolumn{2}{c}{ Unstandardized } & \multicolumn{2}{c}{$\begin{array}{c}\text { Standardized } \\
\text { Coefficients }\end{array}$} \\
Model & B & Std. Error & Beta & t & Sig. \\
\hline $\mathbf{1}$ & (Constant) & $-0,360$ & 0,361 & & $-0,995$ & 0,326 \\
\hline \multicolumn{2}{c}{ Kecerdasan emosional } & $-0,023$ & 0,073 & $-0,052$ & $-0,318$ & 0,752 \\
& Komitmen organisasional & 0,045 & 0,066 & 0,136 & 0,673 & 0,505 \\
& Budaya organisasi & 0,125 & 0,108 & 0,248 & 1,154 & 0,256 \\
\hline
\end{tabular}

Sumber: Data diolah, 2019

Tabel 11. menunjukkan bahwa nilai Sig. dari variabel kecerdasan emosional, komitmen organisasi, dan budaya organisasi lebih dari 0,05 yang berarti tidak terdapat pengaruh antara variabel bebas terhadap absolute residual. Jadi dapat dinyatakan bahwa model yang dibuat tidak mengandung gejala heteroskedastisitas.

Berdasarkan pengujian hipotesis variabel kecerdasan emosional terhadap OCB menyatakan bahwa kecerdasan emosional berpengaruh positif dan signifikan terhadap OCB, ini berarti apabila kecerdasan emosional meningkat, maka OCB karyawan akan mengalami peningkatan juga. Dari hasil penelitian ini terbukti bahwa indikator yang dominan mempengaruhi kecerdasan emosional adalah motivasi. Motivasi meliputi kemampuan karyawan dapat memotivasi dirinya sendiri dalam mencapai sasaran karir. Dengan demikian adanya motivasi yang tinggi, maka mereka akan mampu melakukan OCB.

Hasil ini mendukung hasil penelitian yang dilakukan oleh (Jung dan Hye, 2012) menunjukkan bahwa kecerdasan emosional berpengaruh positif dan signifikan terhadap OCB karyawan. Berdasarkan hasil analisis faktor menunjukkan bahwa kecerdasan emosional menjadi faktor penting dalam meningkatkan OCB. 
(Suwandewi dan Dewi, 2016) menyatakan bahwa kecerdasan emosional berpengaruh positif dan signifikan terhadap OCB. Artinya, apabila kecerdasan emosional meningkat, maka OCB karyawan akan mengalami peningkatan juga. Sementara Penelitian (Asthenu 2017), (Tumaggor dkk., 2017), (Sabahi dan Dashti, 2016), (Bavarsad dan Rahimi, 2016), (Hosseini dan Zirak, 2016) juga menununjukkan terdapat pengaruh yang positif dan signifikan kecerdasan emosional terhadap OCB karyawan. Semakin baik kecerdasan emosional, maka akan memberikan dampak yang baik dalam meningkatkan OCB pegawai.

Berdasarkan pengujian hipotesis variabel komitmen organisasional terhadap OCB menyatakan bahwa komitmen organisasional berpengaruh positif dan signifikan terhadap OCB, ini berarti apabila komitmen organisasional meningkat, maka OCB karyawan akan mengalami peningkatan juga. Dari hasil penelitian ini terbukti bahwa komitmen organisasional yang dimiliki karyawan Fullmoon Villa Ubud tinggi, terutama berkaitan dengan rasa kekeluargaan yang dimiliki karyawan terhadap perusahaan.

Karyawan yang memiliki rasa kekeluargaan yang tinggi terhadap perusahaan akan cenderung lebih sering untuk melakukan OCB. Hasil ini mendukung hasil penelitian yang dilakukan oleh (Pratama dan Mujiati, 2019) menyatakan komitmen organisasional berpengaruh positif dan signifikan terhadap OCB. Hal ini memiliki makna bahwa pegawai yang memiliki komitmen organisasional yang tinggi akan dengan sendirinya menimbulkan perilaku OCB pada pegawai. Penelitian yang dilakukan (Faradita, 2017), menunjukkan bahwa komitmen organisasional berpengaruh signifikan terhadap OCB. Karyawan yang memiliki komitmen tinggi akan lebih sering berbicara secara positif tentang perusahaannya, membantu individu lain dan jauh melebihi harapan normal dalam pekerjaan mereka, selain itu karyawan melakukan pekerjaan dilandasi keinginan sendiri atau tanpa paksaan (Devi dan Adnyani, 2015). Hasil penelitian (Barusman dan Mihdar, 2014), (Ortiz et al., 2015), (Han et al., 2016), (Diatmika dan Suwandana, 2016) menyatakan bahwa terdapat pengaruh positif dan signifikan komitmen organisasional terhadap OCB. Hal ini berarti komitmen organisasional yang tinggi dapat meningkatkan OCB karyawan.

Berdasarkan pengujian hipotesis variabel budaya organisasi terhadap OCB menyatakan bahwa budaya organisasi berpengaruh positif dan signifikan terhadap OCB, ini berarti apabila budaya organisasi meningkat, maka OCB karyawan akan mengalami peningkatan juga. Dari hasil penelitian ini terbukti bahwa budaya organisasi yang dimiliki karyawan Fullmoon Villa Ubud sangat kuat, terutama berkaitan dengan kerjasama. Karyawan yang mampu bekerjasama dalam mencapai tujuan perusahaan akan cenderung berperilaku OCB. Hasil ini mendukung hasil penelitian yang dilakukan (Mahardika dan Wibawa, 2019) menyatakan bahwa budaya organisasi memiliki pengaruh positif dan signifikan terhadap OCB. Hal ini menunjukan bahwa ketika budaya organisasi diterapkan dengan sangat baik di dalam organisasi maka akan meningkatkan sikap OCB pada karyawan dalam organisasi. (Wijaya dan Yuniawan, 2017) dalam penelitiannya juga menemukan bahwa budaya organisasi berpengaruh positif dan signifikan terhadap OCB. Hal ini dapat dilihat dari semakin kuat budaya organisasi akan semakin meningkatkan OCB karyawan. Penelitian serupa yang dilakukan oleh (Kim 2014), (Hamza, 2015), 
(Maulani dkk., 2015), (Yaseen et al., 2015), (Kurniawan et al., 2016) menunjukkan menunjukkan bahwa budaya organisasi berpengaruh positif dan signifikan terhadap OCB, yang dimana budaya organisasi yang kuat memiliki peran penting dalam meningkatkan OCB.

\section{SIMPULAN}

Simpulan yang dapat ditarik berdasarkan hasil analisis penelitian dan hasil pembahasan yang telah dipaparkan adalah sebagai berikut: Kecerdasan emosional berpengaruh positif dan signifikan terhadap OCB karyawan Fullmoon Villa Ubud. Komitmen organisasional berpengaruh positif dan signifikan terhadap terhadap OCB karyawan Fullmoon Villa Ubud. Budaya organisasi berpengaruh positif dan signifikan terhadap OCB karyawan Fullmoon Villa Ubud.

Saran yang dapat diberikan berdasarkan hasil analisis dan pembahasan adalah sebagai berikut: Pihak Fullmoon Villa Ubud diharapkan mampu membuat karyawan melaksanakan tugas melebihi tugas yang diberikan tanpa menunggu perintah dari atasan dengan cara membuat suasana kerja dan lingkungan di sekitar karyawan menyenangkan sehingga karyawan betah untuk bekerja. Saran bagi pihak Fullmoon Villa Ubud mengenai kecerdasan emosional yaitu, memperhatikan karyawannya serta memberikan arahan atau pelatihan kepada karyawan untuk menjalin hubungan yang baik dengan karyawan dan calon karyawan serta membantunya dengan kebutuhan mereka.

Saran bagi pihak Fullmoon Villa Ubud mengenai komitmen organisasional yang dimiliki karyawan, yaitu mempertahankan komitmen yang telah dimiliki seluruh karyawan saat ini. Pemimpin diharapkan mampu meningkatkan keterlibatan emosional karyawan berupa perasaan setia pada organisasi dengan meningkatkan kepeduliannya terhadap karyawan, selalu memberikan motivasi yang positif, sehingga karyawan merasa ingin terus bekerja pada organisasi sekalipun ada penawaran dari organisasi lain. Saran bagi pihak Fullmoon Villa Ubud mengenai budaya organisasi bahwa pimpinan harus lebih memperhatikan kinerja masing-masing karyawan lebih baik lagi, memberikan arahan serta masukan untuk karyawan dalam menyelesaikan pekerjaannya, hubungan baik antara pemimpin dan karyawan harus lebih dijaga dan ditingkatkan sehingga karyawan merasa pekerjaan yang dilakukannya didukung dan dihargai oleh pimpinan.

Saran bagi Pihak Fullmoon Villa Ubud, yaitu sebaiknya perusahaan membuat struktur organisasi sehingga pembagian wewenang, dan tanggungjawab dalam organisasi menjadi jelas. Saran bagi penelitian selanjutnya, penelitian ini hanya sebatas meneliti kecerdasan emosional, komitmen organisasional dan budaya organisasi terhadap organizational citizenship behavior. Peneliti selanjutnya diharapkan untuk menambah variabel lain, dikarenakan peneliti ini hanya memandang OCB yang dipengaruhi oleh kecerdasan emosional, komitmen organisasional dan budaya organisasi. Peneliti selanjutnya diharapkan mengganti metode yang dipakai dengan metode yang lain, seperti: teknik analisis jalur (path) atau MRA, karena peneliti hanya menggunakan teknik analisis linier berganda dimana penelitian ini sudah banyak dilakukan. 


\section{REFERENSI}

Alavi, S. Z., Hoda, M., Forogh, A., \& Azar, P. S. 2013. Relationship between Kecerdasan emosional and organizational Commitment in Iran's Ramin thermal power plant. Procedia. Journal of Social and Behavioral Sciences, 84(3): 815-819.

Ardana, K., Mujiati. N.W., \& Utama. I. W. M,. 2012. Manajemen Sumber Daya Manusia. Edisi I. Yogyakarta: Graha Ilmu.

Ariati, Wiwik, S., \& Endah, M. 2012. Hubungan antara Kecerdasan Emosional dengan Organizational Citizenship Behavior (OCB) pada Karyawan CV. Aneka Ilmu Semarang. Jurnal Psikologi Undip, 11(1): 19-27.

Arifin, H. M. 2015. The Influence of Competence, Motivation, and Organizational Culture to High School Teacher Job Satisfaction and Performance. International Education Studies, 8(1): 38-45.

Asthenu, J.R. 2017. Pengaruh Komitmen organisasionalonal dan Kecerdasan Emosional Terhadap Organizational Citizenship Behavior (OCB). Jurnal Polibisnis, 9(1): 66-80.

Bakan, Ismail dkk., (2013). The Effect of Organizational Commitmen on Women Employees Organizational Citizenship Behavior. Indian Journal of Applied Research, 3(2), 202-204.

Barusman \& Mihdar. 2014. The Effect of Job Satisfaction and Organizational Justice on Organizational Citizenship Behavior with Organization Commitment as the Moderator. International Journal of Humanities and Social Science, 4(9): 118-126.

Bavarsad, B. \& Rahimi, F. 2016. "A Study on The Relationship of Social Capital and Citizenship Behavior With Emotional Intelligence", Entrepreneurship and Innovation Management Journal, vol. 4(1): 1-14.

Brahmasari, I. A., \& Siregar, P. 2009. Pengaruh Budaya Organisai, Kepemimpinan Situasional dan Pola Komunikasi terhadap Disiplin Kerja dan kinerja karyawan pada PT. Central Proteinaprima Tbk. Jurnal Aplikasi Manajemen, 7(1): $238-250$.

Boyatzis, R., Goleman, D \& Rhee, K. 2000. Clustering Competence In Kecerdasan emosional: Insights From The Emotional Competence Inventory (ECI). In R. Bar-On and J.D.A. Parker (Eds.), Handbook of Kecerdasan emosional. San Francisco: Jossey-Bass.

Chamdan, P. 2013. Influence analysis of organizational culture organizational commitment job and satisfactionorganizational citizenship behavior (OCB) toward improved organizational performance. International Journal of Business, Humanities and Technology, 3(5), 86-100. 
Devi, W. S., \& Adnyani, I. G. A. D. 2015. Pengaruh Kepuasan Kerja Karyawan terhadap Komitmen organisasionalonal dan Organizational Citizenship Behavior (OCB) pada PT. Maharani Prema. E-Jurnal Manajemen Unud, 4(12): 4105-4134.

Diatmika, CY., I Nyoman \& Suwandana I. G. M. 2016. Pengaruh Komitmen organisasional dan Motivasi Kerja Terhadap Organizational Citizenship Behavior di Alam Puri. E-Jurnal Manajemen Unud, 5(11): 7128-7155.

Faradita, Y.R. 2017. Pengaruh Kepuasan Kerja dan Komitmen organisasionalonal terhadap Organizational Citizenship Behavior (Studi pada Karyawan PT PLN Area Sidoarjo). Jurnal Administrasi Bisnis, 52(1): 125-129.

Hamza, A.N. 2014. Pengaruh Komitmen organisasional, Kepuasan Kerja Dan Budaya Organisasi Terhadap Organizational Citizenship Behavior (Ocb) Studi Pada PT. Sinar Puspita Abadi Factory Banyuputih, Batang. E-jurnal Fakultas Ekonomi Dan Bisnis UDINUS Semarang, 1(2): 13-20.

Han, S. H., G. Seo., J. Li \& S.W. Yoon. 2016. The mediating effect of organizational commitment and employee empowerment: how transformational leadership impacts employee knowledge sharing intention. Human Resource Development International, 19(2): 98-115.

Harper, P. J. 2015. Exploring forms of organizational citizenship behaviors (OCB): antecedents and outcome. Journal of Management and Marketing Research, 18(1): $1-16$.

Hasani, K., Boroujerdi, S. S., \& Sheikhesmaeli, S. 2013. The effect of organizational citizenship behavior on organizational commitment. Global Business Perspective, 1(1): 452-470.

Hosseini, E.S., \& Zirak, M. 2016. The relationship between emotional intelligence and organizational citizenship behavior and organizational commitment in city secondary school teachers. International Research Journal of Applied and Basic Sciences. 10 (7), 962-971.

Ibrahim, I. 2013. Pengaruh Kecerdasan Emosional terhadap Organizational Citizenship Behaviord dan Dampaknya pada Kinerja Perawat Rumah Sakit Umum Anutapura \& Rumah Sakit Undata Palu. E-Jurnal Katalogis, 1(1): 135-145.

Jain, Ajay, K. 2015. Volunteerism and Organizational Culture: Relationship to Organizational Commitment and Citizenship Behavior in India. Cross Cultural Management, 22(1): 144-116.

Jung, H. S., \& Hye, H. Y. 2012. The effects of Kecerdasan emosional on counterproductive work behaviors and organizational citizen behaviors among food and beverage employees in a deluxe hotel. International Journal of Hospitality Management, 31(2): 369-378. 
Kim, H. 2014. Transformational Leadhership, Organizational Clan Culture, Organizational Affective Commitment, and Organizational Citizenship Behavior: A Case of South Korea's Public Sector. Public Organization Review, 14(3): 397-417.

Kumara, I.W.S., \& Utama, I W. M. 2016. Pengaruh Pelatihan Terhadap Kinerja Karyawan Dengan Mediasi Kepemimpinan Pada Hotel Satriya Cottages Kuta-Bali. E-Jurnal Manajemen Unud, 5(3): 1399-142.

Kurniawan, KA., Brahmasari, I.A., \& Brahmaratih, IA. 2016. The Influence Of Organizational Culture, Task Complexity and, Competence On Job Satisfaction, Organizational Citizenship. International Journal of Business and Management Invention, 5(1): 01-11.

Mahardika, B.P., I Nyoman \& Wibawa, I.M.A. 2017. Pengaruh Budaya Organisasi kepuasan Kerja Dan komitmen Organisasional Terhadap organizational citizenship Behavior pada Karyawan. E-Jurnal Manajemen Unud, 8(1): 7340-7370.

Maulani, V. H., Widiartanto., \& Dewi R.S 2015. Pengaruh Budaya Organisasi Dan Komitmen organisasional Terhadap Kinerja Karyawan Melalui Organizational Citizenship Behavior (OCB) Sebagai Variabel Intervening. Jurnal Ilmu Administrasi Bisnis, 4(3): 224-235.

Oemar, Y. 2013. Pengaruh Budaya Organisasi, Kemampuan Kerja dan Komitmen Organisasi Terhadap OCB Pegawai pada Bappeda Kota Pekanbaru. Jurnal Aplikasi Manajemen, 11(1): 65-76.

Organ, D.W. 2006. Organizational Citizenship Behavior. Its Nature, Antecedents, and Consequences. California: Sage Publications, Inc.

Ortiz, M. Z., Rosario, E., Marquez, E., \& Gruneiro, P. C. 2015. Relationship between organizational commitments and organizational citizenship behaviour in a sample of private banking employees. International Journal of Sociology and Social Policy, 35(1): 91-106.

Podsakoff, P.M., Ahearne, M., \& MacKenzei, S.B. 1997. Organizational Citizenship Behavior and the quantity and quality of work group performance. Journal of Applied Pscyhology, 82: 262-270.

Pratama, K., I G \& Mujiati, N.W. 2019. Peran Komitmen Organisasional Memediasi Pengaruh Kepemimpinan Transformasional Terhadap OCB. EJurnal Manajemen Unud, 8(11): 6887-6909.

Robbins, S.P. 2006. Perilaku Organisasi, Edisi kesepuluh; alih bahasa Benyamin Molan, Edisi Bahasa Indonesia; PT.Mancanan Jaya Cemerlang, Indonesia. 
Sabahi, A.H. \& Dashti, N.S. 2016. "The Effect of Emotional Intelligence and Job satisfaction on Organizational citizenship behavior", Management Science Letters, 6(7): 475-480.

Salovey \& Mayer. 2006. Emotional Intellegent,: Whay Can Matter More Than IQ, NY. Bantam Book.

Suparta, P.J., Gede, S., \& Wayan, M. U. 2013. Pengaruh Moral Karyawan dan Komitmen Organisasi Terhadap Organizational Citizenship Behavior dan Kinerja Individual Karyawan (Studi Kasus di Rama Beach Resort \& Villas). E-jurnal Ekonomi dan Bisnis Universitas Udayana. 2(11): 85-92.

Supartha, W.G. 2008. Budaya Organisasi: Teori Praktis, Kasus, dan Aplikasi Penelitian. Udayana University Press. Hal : 27.

Sutrisno, E. 2013. Manajemen Sumber Daya Manusia, Cetakan Kelima. Yogyakarta: Prenada Media

Suwandewi, N.K.N., \& Dewi, I.G.A.M. 2016. Pengaruh Kecerdasan Emosional dan Dukungan Organisasional terhadap Organizational Citizenship Behavior. EJurnal Manajemen Unud, 5(6): 3958-3985.

Titisari, P. 2014. Peranan Organizational Citizenship Behavior (OCB) dalam Meningkatkan Kinerja Karyawan. Jakarta: Mitra Wacana Media.

Tumanggor, M. D., Abdurahman, D., \& Iss, A. 2017. Pengaruh Kecerdasan Emosional dan Budaya Organisasi Terhadap Organizational Citizenship Behavior PT. XL AXIATA RSM Greater Bandung. Prosiding Manajemen, 3(1): 12-19.

Wibawa, I. W. S., \& Putra, M. S. 2018. Pengaruh budaya organisasi terhadap komitmen organisasional dimediasi kepuasan kerja (studi pada PT. bening badung-bali). E-Jurnal Manajemen Unud, 7(6): 3027-3058.

Widyanto, R, Lau, J.S., \& Kartika, E.W. 2013. Pengaruh Kepuasan Kerja Organizational Citizenship Behavior (OCB) melalui Komitmen organisasionalonal Karyawan cleaning service di ISS Surabaya, Jurnal Hospital dan Manajemen Jasa,1(1): 1-15.

Wijaya, N.A., \& Yuniawan, A. 2017. Analisis Pengaruh Budaya Organisasi Dan Dukungan Organisasi Terhadap Organizational Citizenship Behavior Dengan Komitmen organisasional Sebagai Variabel Intervening (Studi Pada Karyawan Bagian Antaran PT. Pos Indonesia Processing Center Semarang). Diponegoro Journal of Management, 6(4): 1-15.

Yaseen, Asif., Malka, L., Hassan, Lbn, E., \& Massod, U, H. 2015. Impact of Organizational Culture and Social Influence on Organizational 
E-Jurnal Manajemen, Vol. 9, No. 7, 2020 : 2810-2829

Citizenship Behavior with Mediating Effect of Interactional Justice. Science International, 27 (4): 3475-3481. 